\title{
Review
}

\section{Supplier Encroachment in the Supply Chain in the E-Commerce Age: A Systematic Literature Review}

\author{
Huijie $\mathrm{Li}^{1}$ and $\mathrm{Zhiguo} \mathrm{Li}^{2, *}$ \\ 1 School of Business Administration, Chongqing Technology and Business University, \\ Chongqing 400067, China; 2019603004@mail.ctbu.edu.cn \\ 2 School of Management Science and Engineering, Chongqing Technology and Business University, \\ Chongqing 400067, China \\ * Correspondence: lizhiguo@ctbu.edu.cn
}

check for updates

Citation: Li, H.; Li, Z. Supplier Encroachment in the Supply Chain in the E-Commerce Age: A Systematic Literature Review. J. Theor. Appl. Electron. Commer. Res. 2021, 16, 2655-2671. https://doi.org/ $10.3390 /$ jtaer16070146

Academic Editor: Danny C. K. Ho

Received: 11 June 2021

Accepted: 30 August 2021

Published: 7 October 2021

Publisher's Note: MDPI stays neutral with regard to jurisdictional claims in published maps and institutional affiliations.

Copyright: (c) 2021 by the authors. Licensee MDPI, Basel, Switzerland. This article is an open access article distributed under the terms and conditions of the Creative Commons Attribution (CC BY) license (https:/ / creativecommons.org/licenses/by/ $4.0 /)$.

\begin{abstract}
The evolution of e-commerce drives suppliers to develop online direct selling channels to encroach on the retail market, in addition to the traditional distribution channels through the retailer. A systematic literature review (SLR) approach is adopted in this paper to review the existing studies using theoretical models to capture supplier encroachment behavior, as well as the related industry practice phenomena and strategic factors in the supply chain. We present the major research streams according to the selected encroachment literature from two aspects: channel conflict and coordination as well as information structures. We also generalize the significant practical strategies and strategic factors that have been investigated, combined with supplier encroachment, such as investment and spillover effects, the retailer's store brand introduction, strategic inventory, and contract mechanism designs. More importantly, we summarize the classical theoretical models which include the basic models, the signaling game model, and the Hotelling model, and these have been widely used by scholars to capture the supplier's encroachment behavior. Finally, we provide several suggestions which may be valuable for researchers to identify future potential research directions.
\end{abstract}

Keywords: supplier encroachment; supply chain management; systematic literature review

\section{Introduction}

E-commerce has become increasingly prevalent in recent decades. As the Nation Bureau of Statistics showed in the report of "statistical bulletin of national economic and social development in 2020", the annual online retail sales of physical goods reached CNY 9759.0 billion, an increase of $14.8 \%$ over the previous year and accounting for $24.9 \%$ of the total retail sales of social consumer goods. The vigorous development of online retail has created many opportunities for suppliers to establish their own channels to sell products directly to end consumers, in addition to the traditional reselling channel through retailers, which is usually regarded as "supplier encroachment" [1,2]. In industrial practice, upstream suppliers can take various forms to introduce direct sales channels, such as company-owned franchises, factory outlets, and online stores (e.g., official websites, apps, WeChat, and microblog stores or e-platforms [3]). In light of the survey reported by the New York Times, about $42 \%$ of the top suppliers have established direct selling channels in the retail market through their own online or physical stores [4]. For example, electronic product suppliers, such as Apple, Dell, HP, and Samsung, sell their products through third-party retailers but also have adopted online channels to conduct retail operations directly [5-11]. Another example is the fashion apparel industry, in which firms, such as Calvin Klein, Tommy Hilfiger, and Coach, sell through traditional retailers as well as their own direct selling channels [12-15].

The introduction of direct channels is a double-edged sword for retailers and suppliers in the supply chain. It is natural that suppliers' participation in the retail market poses a serious threat to downstream retailers. This is because the existence of a direct channel 
inevitably reduces the products sold in the traditional retail channel $[5,16]$, and results in channel competition and conflict, which may damage retailers' profitability [2,13-17]. Contrary to the above conventional wisdom, some papers in the literature show that encroachment would benefit not only the supplier but the retailer [1,6-8]. More interestingly, there is related research suggesting that encroachment may be in the retailer's best interest but does not necessarily benefit the supplier [18]. For example, encroachment may not be appealing to the supplier if the retailer has strong fairness concerns combined with a unique marketing advantage [19]. Additionally, the upstream supplier has to invest more compared with the traditional retailer, so as to attract more of the final consumers to purchase products directly through their own online channels or brick-and-mortal stores [3]. Generally speaking, supplier encroachment is not always detrimental to the retailer and whether encroachment can lead to the Pareto improvement of the whole supply chain is contingent on some certain conditions and various factors, such as sales efficiency of retail operations $[1,7,20]$, different contract mechanism designs [2,12], and investment and spillovers [5,21-23].

By investing heavily in infrastructure construction, early market research and advertising can be carried out to develop new channels and suppliers can reach end consumers more easily, learn more about consumer demand preferences, and improve their marketing and sales skills. However, it is still challenging for suppliers to accurately gain retail market information when encroachment occurs in the supply chain. Specifically, due to long-term contact with end consumers and specialized knowledge in the selling process, the downstream retailers, such as Walmart, Tmall, and Amazon, often have better knowledge of the market than the upstream suppliers. Much of the previous research mainly focuses on supplier encroachment under symmetric information structures [1,6,7], while the other work complements this stream of research by allowing for one of the supply chain members to have access to private information [2,12,22,23]. In addition, information sharing (or disclosure) combined with supplier encroachment is also widely investigated by scholars [8,24-26]. Therefore, in addition to altering the traditional supply chain channel structure, supplier encroachment also has a substantial effect on information management in the supply chain.

Motivated by the universality of supplier encroachment in the e-commerce age and the insufficiency of a comprehensive survey on this topic, we adopt a systematic literature review (SLR) approach to generalize the existing literature using theoretical models to capture supplier encroachment behavior, as well as the related industry practice phenomena and strategic factors in the supply chain. This study seeks to achieve the following goals: (i) present the critical streams of the existing supplier encroachment research in the last two decades; (ii) summarize the important industry practical strategies and factors influencing supply chain members' strategies and explore research gaps; (iii) generalize the classical theoretical models adopted by the previous supplier encroachment studies; (iv) provide some implications for both researchers and practitioners about supply chain management.

Our analysis proceeds as follows. Section 2 presents the full search strategies and processes of the review in detail and illustrates the results obtained from the SLR. Section 3 discusses supplier encroachment from its development streams, related industry practical strategies, strategic factors and classical theoretical models. Section 4 provides the conclusions and implications derived from the extant encroachment literature for supply chain management.

\section{Methodology}

This paper adopts a systematic literature review (SLR) approach to identify trends and research gaps in the current supplier encroachment literature. This structured literature review is an effective and scientific approach to identify existing findings and productive streams for future research [27], which has been widely employed in the previous literature [28-30]. SLR is proposed by Denyer and Tranfield [31], involving five sequential steps: (1) formulation of the research questions or objectives; (2) locating studies; (3) selection 
and evaluation of studies; (4) analysis and synthesis; (5) reporting and using the results. Correspondingly, we establish an SLR framework related to supplier encroachment on the basis of the above steps, and the specific flow diagram is illustrated in Figure 1.

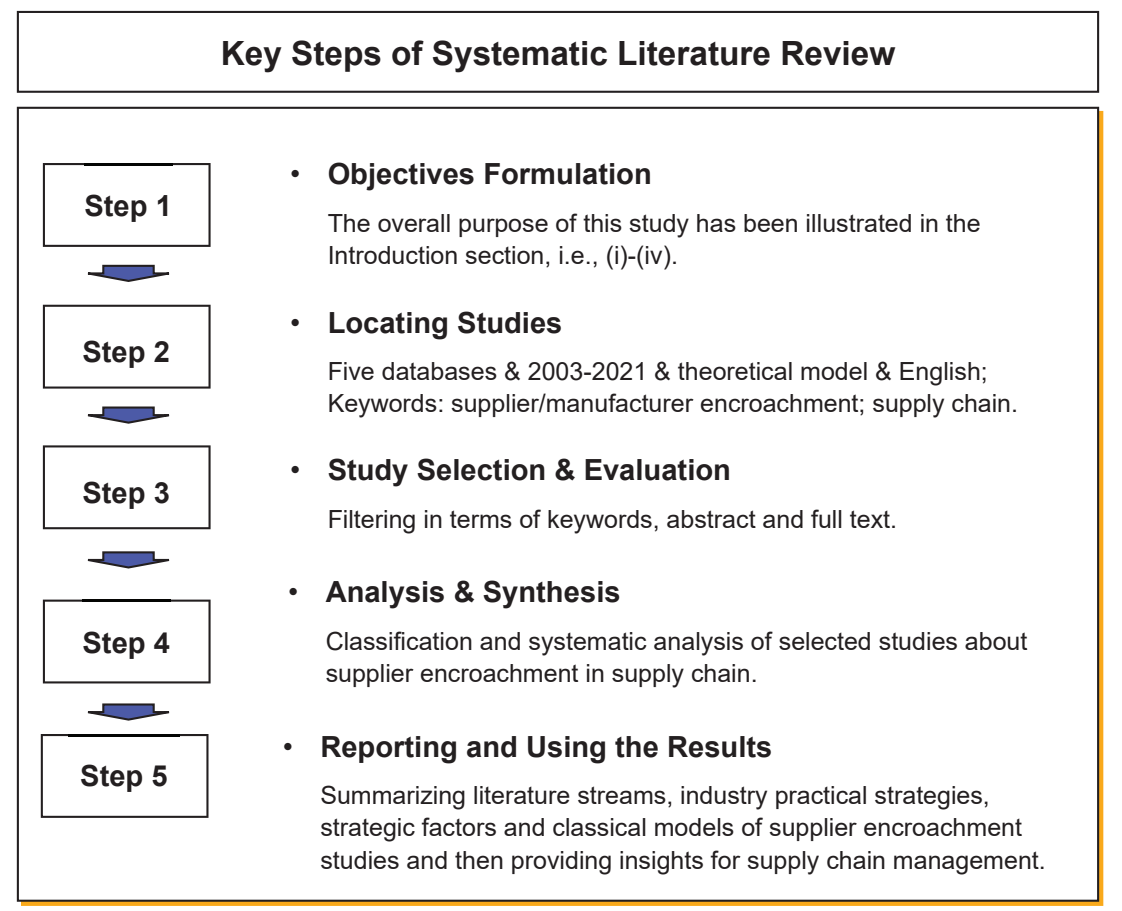

Figure 1. The flow diagram of systematic literature review.

More specifically, the most crucial step of a SLR is to determine well-formulated and realizable goals of this paper. That is to say, this review research is conducted on the foundation of the first step in Figure 1. As shown in the introduction section, we aim to identify the current streams regarding the supplier encroachment research, generalize important industry practical strategies, strategic factors and classical models of the existing supplier encroachment literature, and then provide several insights for both the study and practice of supplier encroachment in the supply chain management field.

In the second and the third steps, we specify several electronic databases, inclusion and exclusion criteria to identify, and select primary studies. On the one hand, there are five kinds of online databases and search engines used in this paper: Elsevier ScienceDirect, Wiley Online Library, informs PubsOnLine, Taylor \& Francis, and SpringerLink. These databases contain large coverage of the peer-reviewed literature which is academic, professional, and certainly written in English. On the other hand, regarding the inclusion and exclusion criteria of these selected studies, we concentrate on those articles extended from 2003 to 2021 in scholarly and research journals. Meanwhile, this paper employs a basis keyword search, as suggested by Rowley and Slack [32], by using the following precise terms: ("supplier encroachment" OR "manufacturer encroachment") AND ("supply chain"). In addition, those articles that use theoretical modeling to study supplier encroachment in the supply chain are this review's core.

Finally, by applying these criteria to the title, abstract, and full text of papers, we obtain 178 academic journal articles that had undergone peer-review in English. Afterward, a total of 50 studies remained based on full text reading. Table 1 illustrates the journals and the the numbers of publications on supplier encroachment in each journal. Moreover, Figure 2 shows the distribution of selected studies through the years from the reviewed journals. 
Table 1. The number of these studies selected in each journal.

\begin{tabular}{clc}
\hline Database & Journal & Number \\
\hline & European Journal of Operational Research & 8 \\
& Omega & 7 \\
& Transportation Research Part E & 6 \\
ScienceDirect & 1 \\
& Journal of Accounting and Economics & 1 \\
& Electronic Commerce Research and Applications & 1 \\
& Journal of Retailing and Consumer Services & 3 \\
& International Journal of Production Economics & 1 \\
\hline & Computers \& Industrial Engineering & 9 \\
& Production and Operations Management & 1 \\
\hline Wiley & Managerial and Decision Economics & 3 \\
& Management Science & 3 \\
& Manufacturing \& Service Operations Management & 2 \\
\hline informs & Marketing Science & 1 \\
\hline Taylor \& Francis & International Journal of Production Research & 2 \\
\hline Springer \& Francis & Annals of Operations Research & 1 \\
\hline & Soft Computing & 50
\end{tabular}

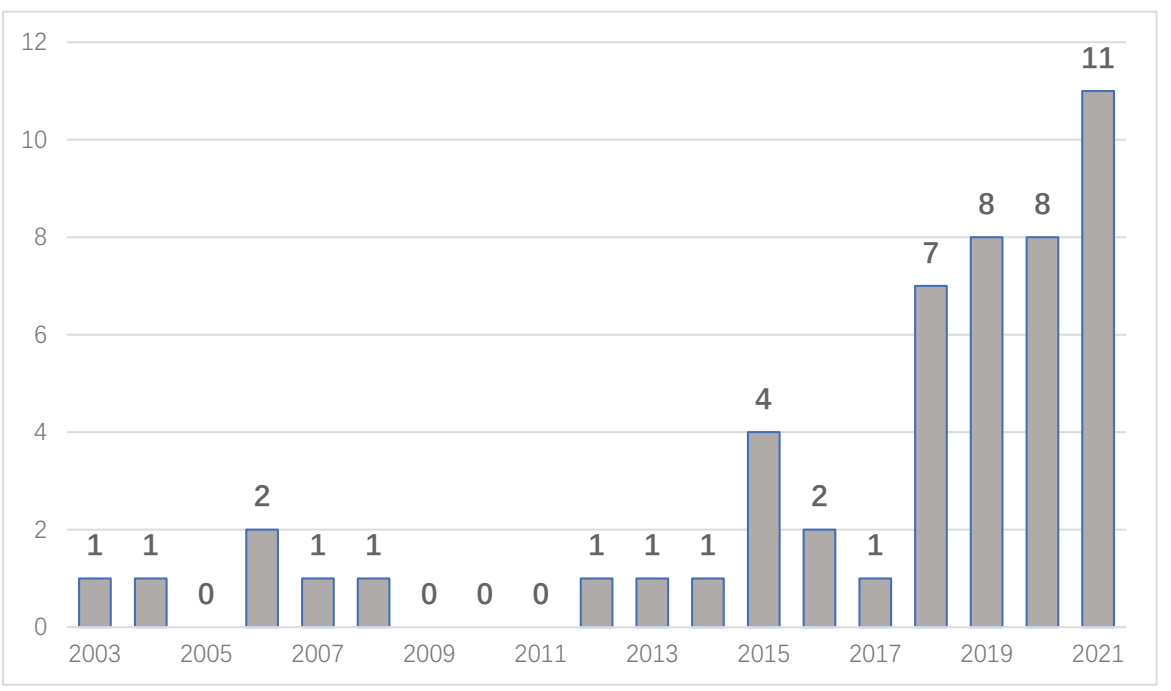

Figure 2. Publication timeline of the selected studies.

\section{Discussion}

This section provides a more detailed analysis of the selected papers. First, Section 3.1 presents the major development streams of supplier encroachment. Second, Section 3.2 discusses the industry practical strategies and critical factors considered in the existing supplier encroachment literature. Third, Section 3.3 generalizes the classical theoretical models adopted to capture the suppliers' encroachment behavior.

\subsection{Major Development Streams of Supplier Encroachment}

This section primarily introduces the common research streams of supplier encroachment from two aspects. The first stream is related to channel conflict and coordination problems caused by supplier encroachment. Besides, the importance of information structures in the supply chain is the second development stream that has received abundant attention in existing encroachment studies. 


\subsubsection{Channel Conflict and Coordination}

A large number of papers investigate the channel conflict and coordination caused by supplier encroachment. Specifically, some literature considers a simple supply chain comprising an upstream supplier and a downstream retailer and aims to examine the influence of the supplier's encroachment behavior on the two members' performances. It has been confirmed that the retailer may be hurt from supplier encroachment due to the increased retail competition in the final market [17,33]. Ha et al. [34] take the endogenous quality into account and demonstrate that encroachment is not conducive to the retailer in all kinds of situations. Moreover, the supplier's encroachment ability is always detrimental to the retailer even if the former only introduces a less efficient direct channel [35]; if the fixed setup cost is not considered in the supply chain dominated by the retailer [36]; when considering the moderate product durability [37] or when given the decentralized encroachment with substitutable green products [38]. Additionally, Li et al. [12] illustrate that the supplier using nonlinear pricing is never better off with the option of encroachment under symmetric information. Guan et al. [18] establish that it is uncertain whether the supplier can benefit from more product quality information disclosure, but it can bring higher ex ante returns to the retailer when facing the launch of the supplier's direct selling channel. It has been proven that when the retailer's fairness concern is strong and her market advantage is remarkable, the supplier's ability to encroach the final market may not even be beneficial for himself [19].

However, the majority of the extant literature proposes that supplier encroachment does not always hurt supply chain members' profits. Sun et al. [22,23] demonstrate that encroachment may be beneficial for the supplier when the direct selling cost is comparatively small, while the retailer only benefit from it with a sufficiently high selling cost. Liu et al. [39] suggest that establishing a direct selling channel by the supplier in the retail market can achieve Pareto improvement when the selling is much more costly through the indirect channel. Furthermore, many studies also indicate that the supplier, as well as the retailer, could benefit from the introduction of direct channels by mitigating double marginalization problems $[1,6,7,21,36,40]$. Besides, encroachment is profitable for the supplier and the retailer simultaneously when considering the product durability by a two-period dual-channel model [41], the advertising cost sharing [9], the retailer's store brand [42], the retailer/buyer's strategic inventory [13,43], as well as the low enough quality cost or the moderate product differentiation level [44].

Most of the other papers in the growing encroachment literature study when or whether direct selling channels should be introduced. Xia and Niu [5] suggest that acting as the leader of Stackelberg, the supplier has the incentive to develop the direct channel if and only if the direct selling cost is small enough. Li et al. [45] show that the supplier may establish his direct selling channel if the retailer introduces a store brand, otherwise he may not introduce an online direct channel. Chen et al. [46] demonstrate that it is necessary for the supplier to open an online direct channel so that the retailer will no longer introduce her discount store, even though the fixed encroachment cost is sufficiently high. It is illustrated that the supplier, as well as the retailer, can achieve profit improvement in the face of the supplier's encroachment given a moderate risk attitude [11]. Zhang et al. [47] find that the online platform's retail service investment may be intended to induce the supplier to set his own direct channel on the platform.

Moreover, there are papers investigating what can effectively counter the supplier's encroachment behavior. Liu and Zhang [17] demonstrate that embracing personalized pricing is an effective measure for the retailer to prevent the supplier from launching his direct selling channel. Zhang et al. [36] suggest that the retailer's service investment could be viewed as an effective anti-encroachment strategy in a retailer-led setting. Huang et al. [8] propose that the supplier may be not intended to encroach the final market when the retailer shares the low type demand information with him, then moderating retail market competition. Zhang and Zhang [48] show that the e-tailer will share the demand information with the supplier to deter the latter from entering an offline direct channel under 
certain conditions. Zhang et al. [49] find that the retailer developing a store brand as the lower-quality substitute of the supplier's national brand can effectively deter encroachment, while establishing a premium store brand cannot. Wang and $\mathrm{Li}$ [50] demonstrate that the presence of a dual-purpose retailer will reduce the margin of a direct channel and it plays a critical role in deterring the supplier's encroachment.

In addition, several papers also study encroachment based on a different supply chain structure, while the term "encroachment" in these papers (e.g., [51-54]) means that upstream contract suppliers sell their own-brand product directly to final consumers and compete simultaneously with downstream original equipment manufacturers. For example, Cui [55] shows that the structure of quality improvement may be an effective measure to prevent the contract manufacturer from encroaching on the retail market.

\subsubsection{Information Structures}

The impacts of supplier encroachment have been widely examined under different information structures. Most existing studies present diversified scenarios and results when the information between the supplier and the retailer is symmetric (e.g., [6,7,19,33,35,38,40,47,50,56,57]). For example, Arya et al. [1] consider a Cournot competition under the symmetric demand information and show that encroachment can reduce the wholesale price for the incumbent retailer. Similarly, given the symmetric information structure, Li et al. [13] compare the effects of centralized encroachment and decentralized encroachment on the supply chain in the presence of retail strategic inventory, as well as the impacts of strategic inventory on supply chain members' profits under different encroachment ways. Yoon [21] examines the interaction between supplier encroachment and product cost-reducing investment which makes the retailer obtain a lower wholesale price caused by the spillover effect. Yan et al. [37] explore the influences of the product durability and the direct selling cost on the durable goods manufacturer and the reseller by developing a two-period model. Zhang et al. [9] study three kinds of advertising types (i.e., the manufacturer/retailer controlled advertising or cooperative advertising) and how they can affect the manufacturer's encroachment strategy. Guan et al. [43] investigate the interplay between the buyer's strategic inventory and the supplier's introduction of a direct selling channel.

In practice, it is very common that there exists asymmetric information regarding market demand (e.g., [2,8,12,14,22-24,48,58-60]), product quality (e.g., [18,61]), or the direct selling cost (e.g., [36,62]) in a supply chain between the supplier and the retailer. Significantly, the downstream retailer generally has an advantage on demand information compared with the upstream supplier because the former is closer to the final market and is more skilled in predicting consumer demand. The available literature primarily captures the demand information asymmetry using the signaling game or the random variable. To the best of our knowledge, Li et al. [2] are the first to illustrate supplier encroachment under this situation through a signaling game where the supplier has the information disadvantage compared to the retailer on the market size. Based on [2], Li et al. [12] extends the work by adopting a nonlinear pricing contract and considers the impacts of supplier encroachment under the asymmetric demand information structure. Sun et al. [22,23] consider supplier encroachment with the cost reduction investment decision or the quantity-based cost decline strategy when the retailer possesses the demand information advantage. Zhang et al. [14] examine the effects of supplier encroachment and the asymmetric demand information structure on the product quality and supply chain members' profits by a signaling game. Xue et al. [59] examine the influence of retail service investment's spillover effect on the timing preference of quantity decision when the supplier encroaches on the retail market under asymmetric demand information. In addition to the above signaling game description, the stochastic variable is adopted by [8] to study whether and when the retailer's private demand information will be shared with the supplier who may develop his direct selling channel in the retail market. In the same way, Arya and Mittendorf [24] explore the interactions of the supplier's entry decision 
and the retailer's disclosure practice who learns favorable market information. Zhang and Zhang [48] discuss two predominant agreements (i.e., agency selling and reselling) and investigate the demand information sharing of the e-tailer in the situation where the supplier could establish brick-and-mortar stores to encroach the retail market. Similarly, demand information sharing decisions of the retailer combined with the production (dis)economy [58] or the retailer's risk-averse behavior [60] have been considered when the supplier has the encroachment capability. Regarding the asymmetric product quality information, there are papers studying supplier's product quality disclosure strategies when he decides to encroach on the retail market and sells products directly to final consumers [18,61]. Concerning the cost information asymmetry, Zhang et al. [36] explore the retailer's service investing which could be viewed as a strategy to deter the supplier's encroachment behavior in a retailer-led setting where the supplier possesses his private direct selling cost information. Gao et al. [62] characterize the supplier's encroachment behavior and the asymmetric cost information structure by a signaling game in which the supplier knows his true selling cost, whereas the retailer knows only its distribution.

\subsection{Supplier Encroachment Coupled with Industry Practical Strategies and Strategic Factors}

This section generalizes the industry practical strategies and various strategic factors which have been investigated in the above selected encroachment literature.

\subsubsection{Supplier Encroachment with Industry Practical Strategies}

The prevalence of supplier encroachment drives many researchers to study its impacts considering the retail service investing (e.g., $[5,36,47,59]$ ), the supplier's production cost reduction investment (e.g., [11,21,22]), the innovation spillover effect [51] or the supplier's product quality investment [14]. To be more specific, Xia and Niu [5] study the impact of supplier encroachment on supply chain members' performances under different power structures in the presence of service spillovers. They discuss four cases in which the supplier or the retailer is viewed as the leader in the Stackelberg game with or without the option of encroachment, respectively. Zhang et al. [36] suggest that the retail service investment may bring Pareto gains to the whole supply chain dominated by the retailer when the supplier owns the private information regarding his direct selling cost. This presents a completely different view from [5] which shows that the retailer will inevitably hurt in the face of the supplier's encroachment and the Pareto gains disappear when the retailer acts as the leader of Stackelberg. Moreover, by developing a game model, the interplay between the retail service investment decision and the supplier's strategy of launching a direct selling channel is examined by Zhang et al. [47]. They establish that the platform's retail service investment is not always regarded as an effective measure to deter the supplier's channel encroachment, and this result is quite contrary to [36] which illustrates that the retail service investment could effectively prevent the supplier from encroaching on the retail market when the retailer is considered as the leader in the supply chain. Xue et al. [59] analyze the supplier-quantity-leader game and the retailer-quantityleader game, respectively, and study the impact of the spillover effect caused by the retail service investing on the decision-making timing preference about quantity by using a signaling game method.

Furthermore, there are papers taking the factor of product cost reduction investment into account to study the supplier's encroachment strategy. Yoon [21] combines supplier encroachment and investment spillovers, and illustrates that encroachment may lead to "profit and loss sharing" between the supplier and the retailer in the retail process, which encourages the supplier to conduct the investment activity to reduce cost spilling over to the downstream retailer at a lower wholesale price. Sun et al. [22] show that the supplier could be endowed with motivation to invest more if and only if the direct selling cost is relatively low when encroachment occurs. They also demonstrate that encroachment makes the supplier monopolize all of the benefits in a signaling game. This is significantly different from [21] which suggests that the retailer's profit could be increased by the spillover 
effect and finally the Pareto improvement can be obtained for the supply chain. Similarly, Chen et al. [11] investigate the common influences of supply chain members' risk attitudes and the upstream production cost reduction investment on the supplier's encroachment strategy, and show that the supplier and the retailer may achieve the "win-win" situation in certain conditions.

Additionally, Hu et al. [51] investigate the outsourcing strategy of innovator and encroachment decisions of contract suppliers in the presence of spillover risks focusing on the ex ante uncertain values of innovation. They aim to obtain some insightful results by differentiating between technical innovation and non-technical innovation, in which the former can only lead to spill over through outsourcing and the latter can also spill over in the retail market. Zhang et al. [14] examine the influence of endogenous quality investment and demand information asymmetry on supply chain members' profits when the supplier has the ability to encroach. They find that the product quality will decline due to the supplier's encroachment behavior when the direct selling cost is in the middle level.

It is straightforward to see that retailers regard supplier encroachment as a threat because of the loss of monopoly in the retail market. Many scholars have characterized a variety of strategy factors adopted by retailers and explored whether the presence of these factors can benefit supply chain members even when the supplier develops his own direct selling channel. These factors mainly include risk attitude (e.g., [11,60,63]), the introduction of retailer's store brand (e.g., [42,45,46,49]), the strategic inventory (e.g., [13,43]), and the retailer's fairness concerns [19]. More specifically, Chen et al. [11] study how the supplier's encroachment behavior is affected by comprehensive effects of the risk attitude and the upstream investment spillover, and demonstrate that encroachment might be a better choice for both the supplier and the retailer given an intermediate confidence degree. A risk-averse retailer combined with the introduction of supplier's direct selling channels is considered by Li et al. [60], in order to analyze their impacts on supply chain members' optimal decisions when the market demand information is asymmetric. Morever, $\mathrm{Li}$ and Jiang [63] examine how the consumer's return policy and the retailer's risk aversion impact firms' behaviors facing the supplier's encroachment in the supply chain. They show that the increase of retailer's risk aversion degree may result in the decrease of retailer's expected utility while the increase of supplier's profit.

With regard to the introduction of retailer's store brand, Wang et al. [42] investigate supplier's online direct channel strategies to sell his own national brand (NB) product and retailer's optimal decisions when she sells both the NB and her own lower-quality store brand (SB) product. They suggest that a lower quality level of the SB product may be more profitable for the retailer to avoid competition with the direct channel established by the supplier. Li et al. [45] develop a game-theoretic model including direct channel and brand introduction strategies. It is indicated that, in the equilibrium state, the retailer's store brand is introduced while the supplier's direct channel may or may not be introduced. Chen et al. [46] introduce the retailing discount store into supplier encroachment problem through which off-price products could be obtained and then competes with supplier's products. It is interesting to find that, even though the fixed encroachment cost is high, the supplier has to open his online direct selling channel to prevent the retailer from introducing a discount store. Zhang et al. [49] examine introduction strategies of the retailer's store brand consisting of a premium store brand or a store brand with the option of supplier encroachment. They show that the presence of the retailer's store brand can be an effective anti-encroachment measure, while the premium store brand cannot be.

Regarding the factor of retailer's strategic inventory, Li et al. [13] incorporate the strategic inventory of the retailer which can be regarded as a countermeasure to obtain a more favorable wholesale price and encroachment decisions of the supplier who may conduct centralized encroachment or decentralized encroachment. Guan et al. [43] explore the interplay between the retailer's strategic inventory and the supplier's direct selling behavior in a two-period model. They illustrate that the retailer may withhold the strategic inventory option in some situations for any limited holding cost, which makes the supplier 
less active in establishing his direct selling channel in contrast to the situation where the strategy inventory is not a choice. In particular, the retailer's fairness concerns may be triggered by the supplier's encroachment decision [19] and encroachment may not be profitable for the supplier when the retailer possessing a remarkable advantage in marketing has strong fairness concerns.

\subsubsection{Supplier Encroachment with Various Strategic Factors}

Product properties are the important factors that have been well emphasized together with supplier encroachment by many scholars. On the one hand, product durability has been studied by [37] using a two-period model in which the supplier can establish his own direct selling channel in addition to traditional channels through the retailer. They suggest that, unlike the results derived from [1], supplier encroachment is always not conducive to the retailer given an intermediate product durability, and then its bright side vanishes for any direct selling cost. Similarly, the product durability and its influences on supply chain members' decisions are examined by [41] through a two-period model in the presence of supplier encroachment. They assume that the product is perfectly durable and does not deteriorate over time, which is one of the most important differences compared to [37]. Accordingly, it has been proved by [41] that both the dealer and the supply chain may be better off from the setup of supplier's direct selling channels.

On the other hand, product quality differentiation combined with supplier encroachment has been explored by [34], which indicates that the supplier who provides two channels with differentiated products has the strong disposition to sell his high-quality products directly to final consumers. Zhang et al. [33] investigate the channel selection and the product assortment problem in face of product differentiation. They illustrate that encroachment, even if incurring channel conflict to a certain degree, can alleviate the product competition among firms because supply chain members can sell differentiated products through different channels. Mandal and Jain [44] study critical influences of the product quality differentiation and the partial outsourcing on supply chain channel structures and firms' strategies when the supplier has the ability to encroach.

Furthermore, the supplier's encroachment strategy is considered together with the substitutable green products by the authors of [38]. It indicates that, with the increase of product substitutability, encroachment is always beneficial for the supplier while it makes the retailer better off only if the direct selling cost exceeds a certain threshold. Besides, compared with the centralized encroachment, the environmental performance and the social welfare of the whole supply chain can be improved under decentralized supplier encroachment.

Contract mechanism designs are also critical factors that have generally appeared in much research related to supply chain management. It is natural that some scholars have studied different contract mechanism types of transaction between the supplier and the retailer when the supplier may develop his direct selling channel to contact final consumers. For example, Li et al. [12] study the nonlinear pricing contract offered by the supplier to elaborate the influence of supplier encroachment on supply chain members' optimal strategies under asymmetric demand information. They suggest that whether the supplier's encroachment capability can benefit or hurt the supplier and the retailer is dependent on the relative efficiency and the demand distribution situation of the two channels. This is different from [2] which shows that, when a wholesale price-only contract is adopted, supplier encroachment may mitigate or amplify the double marginalization problem in face of asymmetric demand information. Particularly, Yang et al. [35] analyze how a nonlinear pricing contract affects the introduction of a supplier's direct channel in a supply chain where two channels' products are imperfectly substitutable. These firms implement the nonlinear pricing contract to negotiate about the wholesale price and the quantity bilaterally, meanwhile the revenue sharing contract is also adopted to further coordinate supply chain members' sales revenue. Mandal and Jain [44] incorporate the two-part tariff contract into 
the partial outsourcing problem in the presence of product quality differentiation when the supplier has the option to compete with the downstream manufacturer.

\subsubsection{Supplier Encroachment with Other Factors}

Certainly, there exist many other factors playing an important role in the extant literature about supplier encroachment. For instance, Liu and Zhang [17] analyze the personalized pricing strategy of the retailer/supplier and the encroachment decision of the supplier to obtain some implications for the channel management. Sun et al. [23] investigate a supply chain in which the unit cost of products produced by the supplier, who has the ability to establish a direct channel, decreases with the increase of cumulative production. Then these products will be sold through the retailer who is better informed about the demand information. Liu et al. [39] discuss the impact of pay-on-delivery service on supply chain members' performances and channel strategies in which the supplier offers this service to final consumers in his direct selling channel. It is assumed that the presence of delivery lead time will reduce the consumers' future expected utility on the supplier's direct channel. Zhang et al. [9] study the interaction of supplier's encroachment strategies and the informative advertising which may be invested by the supplier or the retailer or the both to inform the product information to consumers. Zhang and Zhang [48] incorporate the e-tailer's demand information sharing strategy into the supplier's direct entry decision by considering agency selling and reselling agreements. Wang and Li [50] explore the supplier's encroachment behavior in the supply chain where the dual-purpose retailer pursues not only her own profit but the consumer surplus. It has been found that introducing the direct selling channel may ultimately damage the supplier under the interaction of encroachment and the retailer's interest in consumer surplus. Li et al. [56] examine supplier encroachment in competitive supply chains, which is quite different from previous papers analyzing encroachment only with a monopolistic supplier. Chen et al. [57] study how the supplier manages his direct selling channel and the traditional distribution channel through an independent retailer when there exists the service competition in the two channels, meanwhile the delivery lead time and the product availability are used to measure different channels' service level. In addition, the research regarding information sharing is extended by [58] to this situation where the supplier has the incentive to develop his direct selling channel in face of the production diseconomy or economy, namely the supplier produces products with the increase or decrease of unit marginal cost. Hotkar and Gilbert [15] consider a nonexclusive reseller who orders partially substitutable products from two suppliers, one of whom has the ability to set his own direct channel on the retail market. They propose that encroachment is not conducive to both the reseller and the whole supply chain if the product substitutability is large enough.

\subsection{Classical Theoretical Models Used to Capture Supplier Encroachment}

We summarize classical theoretical models in this section, which capture the supplier's encroachment behavior as well as the related industry practical strategies and various strategic factors in the selected papers. Section 3.3.1 shows the common basic model used to capture supplier encroachment, Sections 3.3.2 and 3.3.3 present some more complex models that can be developed from the basic model to a certain degree.

\subsubsection{The Basic Model}

We introduce the structure of the basic model characterizing supplier encroachment from the following aspects: supply chain structures, the (inverse) demand function, necessary assumptions to promote the model's integrity, and the game model's timing sequence.

Standard supply chain models which relate to supplier encroachment generally consider a supplier (s) who sells a product at the wholesale price $\omega$ through an independent retailer $(r)$ who then sells the product to end consumers. In addition, the supplier also establishes his own online/offline channel to provide final consumers with products directly. The supplier's production cost and the retailer's selling cost are normalized to zero and 
the supplier's per-unit direct selling cost is normally denoted as $c$, which reflects that the supplier has an advantage in production and the retailer has an advantage in the sales process $[1,2,12,22,23,35,43,50,56,60,62]$. The retailer's advantage might come from the superior knowledge of customer preferences, more direct contact with customers, or economics of scope with other retailing activities $[1,35,56,60]$, while the supplier lacks experience in selling directly to consumers [43].

Most studies in the growing literature on supplier encroachment assume that products sold through the traditional retailer and the supplier's direct channel are symmetric substitutes, i.e., the degree of substitution between the supplier and the retailer is the same [35]. Thus, the consumer demand in a retail market is captured by a linear and downward-sloping inverse demand function:

$$
p_{i}=a-q_{i}-k q_{j}, i, j=s, r ; i \neq j,
$$

where $p_{i}$ represents the market clearing price, $a$ is the market sizer, and $q_{i}$ and $q_{j}$ denote the product quantities of firms $i$ and $j$, respectively. The parameter $k \in(0,1]$ measures the products' substitutable degree in the two channel, and with the increase of $k$, the two products become more identical and the competition in the retail market becomes more fierce $[9,21,35]$. Additionally, there exists another demand function form to characterize the market price $p$, in which the retailer orders products quantity $q_{r}$ and then sells to consumers and the supplier sells quantity $q_{s}$ directly to final consumers:

$$
p=a-b Q
$$

where $a$ denotes the market size, $Q=q_{s}+q_{r}$ is the total quantity sold in the retail market, and $b$ can be described as the price sensitivity which is strictly positive constants $[1,50,62]$. There are also some papers considering that the products sold through the two channels are perfect substitutes, and thus the introduction of supplier's direct channel would not impact the total market demand. Therefore, the market clearing price is determined by the linear demand function:

$$
p=a-Q
$$

where $a$ represents the market size and $Q=q_{s}+q_{r}$ is the total number of the product deployed for sale. It is without loss of generality that the slope of this demand function has usually normalized to be $-1[2,12,22,23,43,56,60]$.

The Cournot model shown in Equations (1)-(3) is suitable for describing supplier encroachment, which is reflected in the following aspects. First, the supplier and the retailer generally sell homogeneous products in the presence of supplier encroachment, and there exists no price difference between the direct channel and the distribution channel. Therefore, the quantity competition can better reflect the essence of channel difference, which is also consistent with the industry practice. Second, as shown in our review, the Cournot model has been widely used in the existing encroachment literature. Moreover, by using this model, there are many enlightening conclusions and suggestions have been obtained for supply chain management. For example, information management implications in supply chain shown in $[2,8,22,23,25,26,61]$, investment management implications examined in $[5,11,21,47,59]$, and contract mechanism designs investigated in $[12,35,44]$.

The sequence of events in this basic model can be detailed as follows. First, the supplier decides whether to open his direct selling channel in the retail market. Second, the supplier offers a wholesale contract to the retailer, which contains a unit wholesale price $\omega$. Third, the retailer decides her order quantity, followed by the supplier determining his direct selling quantity if the supplier has the option to encroach. Finally, the market clearing price $p$ is realized according to the demand function and the two parties obtain their final profits. Note that this assumption that the retailer orders before the supplier is consistent with the fact that the supplier typically has no means to credibly commit to not adjust his own stocking quantity in response to the order placed by the retailer $[1,2,12,22,23,35,43,50,56,60,62]$. Backward induction is employed to identify equilibrium outcomes of this sequential game. 
Nevertheless, some studies discuss the situation where the supplier and the retailer engage in Cournot competition by simultaneously deciding their product quantities $q_{s}$ and $q_{r}$, respectively $[9,21]$.

\subsubsection{The Model Under Asymmetric Information}

When taking the asymmetric information between the supplier and the retailer in the supply chain, there are two common methods to capture this information structure in the selected supplier encroachment literature: the signaling game model or the stochastic variable.

The signaling game model is typically used to characterize the demand information asymmetry when encroachment exists, in which the retailer might be better informed about the market size than the supplier. In practice, this is because the retailer is closer to the retail market and may also have better expertise in forecasting the demand than the supplier. Thus, some literature assumes that the market size $a$ is, ex ante, random which can be either large $\left(a=a_{H}\right)$ with probability $\lambda$ and small $\left(a=a_{L}\right)$ with probability $1-\lambda$, where $a_{H}>a_{L}>0$, and $\lambda \in(0,1)$. Furthermore, the expected market size is denoted as $\mu=\lambda a_{H}+(1-\lambda) a_{L}$, and $\sigma^{2}=\lambda\left(a_{H}-\mu\right)^{2}+(1-\lambda)\left(a_{L}-\mu\right)^{2}$ represents the variance of the market size distribution. The retailer can observe the true market size privately, before ordering from the supplier, whereas the supplier knows only the prior distribution of the market size. Although the supplier does not observe the market demand directly, he can use the information revealed from the retailer's order quantity to make his direct sales quantity decision. The retailer then anticipates the supplier's reaction to her order, a signaling game occurs in which the retailer may purposely alter her order quantity to mislead the supplier and maintain her own information advantage $[2,12,14,22,23,59]$. Additionally, the cost information asymmetry can also be captured through the signaling game according to [62]. It assumes that only the supplier has the private information about his own direct selling $\operatorname{cost} c_{i}$ if he establishes the direct channel to sell products, which is consistent with the practice that the supplier's direct selling cost is much harder for others to estimate. The $\operatorname{cost} c_{i}$ can be either high (i.e., $c_{h}$ ) or low (i.e., $c_{l}$ ) and the prior probability $\operatorname{Pr}\left\{c_{i}=c_{l}\right\} \equiv \mu_{o}$. Initially, the retailer knows only prior belief $\mu_{o}$, then she can update $\mu_{o}$ to the posterior belief $\mu$ after observing the price $\omega_{i}$, thus a signaling game occurs.

To be more specific, we present the literature case, as shown in [2], using the signaling game model to capture the demand information asymmetry between the supplier and the retailer in the presence of supplier encroachment. First, this study considers a benchmark without encroachment (denoted as the superscript " $\mathrm{N}$ "), namely only the retailer sells products in the end market and knows the actual market demand. Thus the market clearing price is $p=a_{i}-q_{r}, i \in\{H, L\}$, and the retailer's profit function can be described as $\pi_{r}=\left(a_{i}-q_{r}-\omega\right) q_{r}$. The retailer can obtain the optimal order quantity $q_{r}^{\mathrm{N}}(\omega)=$ $\left(a_{i}-\omega\right) / 2$ by solving $\max _{q_{r}} \pi_{r}$, and then the supplier chooses the optimal wholesale price $\omega^{\mathrm{N}}=\mu / 2$ as the solution to $\max _{\omega} E\left[\omega q_{r}^{\mathrm{N}}(\omega)\right]$. As a result, the retailer's and the supplier's expected profits are obtained. Second, the case of supplier encroachment is introduced, in which the supplier establishes her own sales channel to sell products directly in addition to the traditional distribution channel, and here only the retailer knows actual demand state types. The inverse demand function is $p=a-q_{r}-q_{s}$ and similar to Equation (3) in Section 3.3.1, which suggests implicitly that the two channels are perceived to be perfect substitutes. According to the game sequences shown in Section 3.3.1 and using backward induction, the supplier first decides the optimal direct selling quantity $q_{s}\left(q_{r}\right)=\left(a_{j}\left(q_{r}\right)-q_{r}-c\right) / 2$ by solving $\max _{q_{s}}\left[a_{j}\left(q_{r}\right)-q_{r}-q_{s}-c\right] q_{s}$, where $a_{j}\left(q_{r}\right), j \in$ $\{H, L\}$ is the supplier's belief about the demand state after observating the retailer's order quantity $q_{r}$. Then the retailer, who knows the actual market size $a_{i}, i \in\{H, L\}$, get his optimal order quantity $q_{r}(\omega)$ by solving $\max _{q_{r}}\left[a_{i}-q_{r}-q_{s}\left(q_{r}\right)-\omega\right] q_{r}$ and some constraints. In anticipation of the subsequent subgames, the supplier makes the wholesale price decision by solving $\max _{\omega} E\left[\omega q_{r}(\omega)+\left(a-q_{r}(\omega)-q_{s}\left(q_{r}(\omega)\right)-c\right) q_{s}\left(q_{r}(\omega)\right)\right]$. Hence, two parties' equilibrium profits can be obtained correspondingly. Finally, influences of supplier encroachment on the retailer's and the supplier's strategic behaviors are illustrated 
by comparing their equilibrium profits, respectively, under encroachment case and no encroachment case.

The stochastic variable is also adopted by the extant encroachment literature to capture the uncertain information of supply chain members including the market potential, product quality, or the cost information. Specifically, in order to present the uncertain market demand, some papers denote the parameter $\theta$ as the uncertainty level of market potential. Thus the market demand is given by $a+\theta$, in which $a$ is the base demand that is known to both the supplier and the retailer and $\theta$ is usually subject to a certain distribution in these papers. Generally, the retailer has a greater demand information advantage over the supplier due to the rich first-hand data and the more skilled selling experience. Therefore, it is common that the article assumes the retailer can observe the resolved demand information $\theta[8,24,48]$ or conduct a demand forecast activity [58], while the supplier maintains his prior belief for the market demand size. Moreover, the product quality information may be asymmetric between firms and consumers, because firms are normally more familiar with products and can take some measures to pre-verify the product quality. It is assumed that the product quality is a random variable that follows a uniform distribution between 0 (the lowest quality) and 1 (the highest quality), $m \sim U[0,1]$. As a result, firms can privately observe the product's exact quality level $m$ before putting it into the market, while the consumer holds a prior belief about the distribution of product quality $[18,61]$. Besides, when the supplier sells products directly to final consumers, he incurs a unit selling cost, $c$, which is kept as his private information. The retailer only holds the prior information of $c$ with mean $\mu$, which may be larger or smaller than $c$, and variance $\sigma^{2}[36]$.

\subsubsection{The Model Combined with Additional Strategic Factors}

Researchers have paid great attention to study the interaction between supplier encroachment and other strategic factors in supply chain management. Thus, it is necessary to summarize and refine classical models considering these factors based on the selected literature in this review.

First, the literature on the effects of supplier encroachment and firms' investment behavior is extensive and presents a similar model description. In particular, the quadratic function, namely the investment cost $\frac{\gamma}{2} I^{2}$, has been widely applied in the retail service investing (i.e., [5,36,47,59]), the production cost reduction investment (i.e., [11,21,22]), and the product quality investment (i.e., [14]) literature. They denote $I$ as the investment level/amount and $\gamma$ represents firms' investment efficiency. This quadratic form is not only for expositional convenience, but also in accordance with the practical fact. We present a more specific literature example illustrated in [21], which combines supplier encroachment with the cost-reducing investment of the supplier. The inverse demand function $p_{i}=a-q_{i}-k q_{j}(i, j=s, r ; i \neq j)$ is used by this study, namely Equation (1) in Section 3.3.1. Then profit functions of the retailer and the supplier are $\Pi_{r}=\left(p_{r}-\omega\right) q_{r}=$ $\left(a-q_{r}-k q_{s}-\omega\right) q_{r}, \Pi_{s}=\left(p_{s}-d(1-I)\right) q_{s}+(\omega-d(1-I)) q_{r}-\frac{\gamma}{2} I^{2}=\left(a-q_{s}-k q_{r}-\right.$ $d(1-I)) q_{s}+(\omega-d(1-I)) q_{r}-\frac{\gamma}{2} I^{2}$, respectively, where the product's constant production cost $d \in(0, a)$ is reduced by an investment amount $I \in[0,1]$. This paper then obtains equilibrium solutions in four cases: without any investment under no encroachment case or encroachment case, with investment under no encroachment case or encroachment case. As a consequence, the impact of supplier encroachment and the investment spillover effect are examined.

Second, the retailer's store brand or discount store introduction, as the key element in supply chain management, has attracted a lot of attention among supplier encroachment literature. The Hotelling model has been used by some scholars to describe this industry practice strategy due to the different positioning and pricing of the retailer and the supplier in the retail market. To be specific, Hotelling visualizes a line of fixed length along which consumers are uniformly distributed [64]. There are two competitors in the market and each selects a location and a price in the line. Consumers then choose a preferred seller by 
weighing the price and the transportation cost to arrive at this seller's store. According to consumers' purchase preferences, sellers optimize their location and price for maximizing profits until the equilibrium is achieved. Therefore, in the presence of the retailer's discount store introduction and supplier's encroachment strategy, the Hotelling model may be used as follows. Consumers in the market are uniformly distributed along a Hotelling line between zero and one, $x \in\{0,1\}$, and purchase a unit product with a constant transportation cost, $t$, for per unit distance. The customer has a valuation $V$ for the supplier's product, $\theta V$ for the retailer's off-price product in the discount store in which $\theta<$ 1 denotes the discount factor, and has zero utility if not making any purchase. The retailer is located at the left end of the Hotelling line $(x=0)$. Therefore, when a customer locates at $x$ and buys the supplier's product from the retailer at price $p_{1}$, the utility is:

$$
U_{1}=V-t x-p_{1}
$$

The customer's utility in purchasing an off-price product from the retailer's discount store located at the right end of the Hotelling line $(x=1)$ at price $p_{2}$ is:

$$
U_{2}=\theta V-t(1-x)-p_{2}
$$

Then whether the retailer introduces a discount store or not, the utility of the customer when buying the product in the direct selling channel from the supplier at price $p_{3}$ is:

$$
U_{3}=V-h-p_{3}
$$

where $h$ represents the hassle cost incurred by the customer when shopping online $[42,46]$. It is straightforward that this model captures both the channel difference and the product price difference. In the Hotelling model, the retailer, who introduces the discount store or his own store brand, locates at one or both ends of the Hotelling line and holds different prices for products from the upstream supplier and his own store. The supplier encroaches on the retail market by developing an online channel to sell products directly to end consumers. Consumers do not have to pay the transportation cost when purchasing products from this online channel, while may incur the hassle cost due to shopping online. By making use of consumer's utility indifference conditions, consumer demands positioned in the Hotelling line and the supplier's online channel can be obtained. Hence, the optimal product prices of the retailer and the supplier, which depend on the unit production cost of the product, the transportation cost, the product valuation by the consumer, the hassle cost, etc., are derived by maximizing profits in their respective sales channels. Then the interaction between the retailer's store brand or the discount store introduction and supplier's encroachment strategies would be investigated.

\section{Conclusions and Implications}

This review summarizes supplier encroachment literature using theoretical models through a systematic literature review approach to make the topic more understandable and transparent for practitioners and researchers. We conclude two prevalent research streams of supplier encroachment according to selected representative literature. Namely the channel conflict coordination as well as information structures in the supply chain, which are highly consistent with practical problems caused by encroachment. Moreover, we present industry practical strategies and some critical factors in the supply chain that scholars pay abundant attention to when it comes to supplier encroachment, such as investment and spillover effects, risk attitudes, the retailer's store brand, the strategy inventory, retailer's fairness concerns, different product properties, and various contract mechanism designs. Significantly, we generalize several classical models which have been widely used to capture supplier encroachment in the supply chain. They mainly include the basic model introducing the composition of supply chain members, the form of (inverse) demand functions and the common timeline of game model, the signaling game model 
used to characterize the asymmetric information structure when encroachment occurs, and the Hotelling model which can be used to examine the retailer's store brand or discount store introduction.

By reviewing the current literature in supplier encroachment and combing out the relationship among different kinds of literature, we aim to provide opportunities to identify gaps or find the conflict from the extant literature and then propose new research perspectives for further research directions. The following several research suggestions, which are either made by scholars or elaborated through this literature review analysis, seem to need further investigation by researchers and would lead to promising results.

First, it is worth exploring how the power structure affects supply chain member's performances when encroachment exists. This power is defined by the authors of [65] as the control that one channel member exerts over the selection of particular elements of another marketing strategy. More specifically, the power of one supply chain member is his ability to control the decision variables of another supply chain member. Although the extant literature considers a dominant retailer [36] or a manufacturer/retailer-quantity-leader game [59], they only focus on examining the factor of the retailer's service investment. Therefore, scholars can model the supplier's encroachment behavior from the perspective of channel power by considering richer elements such as the strategic inventory, durable goods, contract types, etc.

Second, the emergence of new business modes in the era of e-commerce makes the supplier have more opportunities to establish his own online direct selling channel in addition to traditional retail channels. Thus it is a popular phenomenon that consumers have a need to place an order through the supplier's online channel and then go to the local store to pick up the product at their convenience [3]. This kind of purchase mode is more dependent on the cooperation between the encroaching supplier and the incumbent physical retailer. However, whether this mode is able to get the retailer's approval and finally achieve a win-win situation among supply chain members is still worth exploring.

Third, it is general in the selected encroachment literature that scholars assume supply chain members are rational and pursue their own profit-maximizing, which can be viewed as for-profit firms. Nevertheless, the topic of dual-purpose corporations with "beyond profit"motivations is intriguing and would be valuable for practitioners and academic researchers to elaborate in the future [66]. The impact of pursuing the "beyond profit" goal on a firm's profits and the consumer surplus in face of the supplier's encroachment behavior has been investigated by the authors of [50]. Future research can explore relevant topics that a dual-purpose corporation seeks not only his own profit but also other significant goals to implement corporate social responsibility, such as the fitness between consumers and products, environmentally friendly products, social welfare, etc.

Author Contributions: Conceptualization, H.L. and Z.L.; methodology, H.L.; writing-original draft preparation, H.L.; writing-review and editing, Z.L. All authors have read and agreed to the published version of the manuscript.

Funding: This research is funded by The National Social Science Fund of China (2021BGL255); Open Project of Research Center for Enterprise Management of Chongqing Technology and Business University (KFJJ2019013); Graduate Innovation Project of Chongqing Technology and Business University (yjscxx2021-112-78).

Institutional Review Board Statement: Not applicable.

Informed Consent Statement: Not applicable.

Data Availability Statement: Not applicable.

Conflicts of Interest: The authors declare no conflict of interest.

\section{References}

1. Arya, A.; Mittendorf, B.; Sappington, D.E.M. The Bright Side of Supplier Encroachment. Mark. Sci. 2007, 26, 651-659. [CrossRef]

2. Li, Z.; Gilbert, S.M.; Lai, G. Supplier Encroachment Under Asymmetric Information. Manag. Sci. 2014, 60, 449-462. [CrossRef] 
3. Xia, J.; Niu, W. A perspective on supplier encroachment in the era of e-commerce. Electron. Commer. Res. Appl. 2020, $40,100924$. [CrossRef]

4. Tedeschi, B. Compressed data; big companies go slowly in devising net strategy. New York Times, 27 March 2000.

5. Xia, J.; Niu, W. Adding clicks to bricks: An analysis of supplier encroachment under service spillovers. Electron. Commer. Res. Appl. 2019, 37, 100876. [CrossRef]

6. Chiang, W.-Y.K.; Chhajed, D.; Hess, J.D. Direct Marketing, Indirect Profits: A Strategic Analysis of Dual-Channel Supply-Chain Design. Manag. Sci. 2003, 49, 1-20. [CrossRef]

7. Tsay, A.A.; Agrawal, N. Channel Conflict and Coordination in the E-Commerce Age. Prod. Oper. Manag. 2004, 13, 93-110. [CrossRef]

8. Huang, S.; Guan, X.; Chen, Y.-J. Retailer Information Sharing with Supplier Encroachment. Prod. Oper. Manag. 2018, $27,1133-1147$. [CrossRef]

9. Zhang, J.; Cao, Q.; He, X. Manufacturer encroachment with advertising. Omega 2020, 91, 102013. [CrossRef]

10. Chai, J.; Chen, H.; Huang, Q.; Yan, W. Should a Manufacturer Encroach on Its Retailer's Operations with Quality Differentiated Products? Discret. Dyn. Nat. Soc. 2017, 2017, 8367547. [CrossRef]

11. Chen, H.; Yan, Y.; Ma, N.; Liu, J. Effects of risk attitudes and investment spillover on supplier encroachment. Soft Comput. 2018, 24, 2395-2416. [CrossRef]

12. Li, Z.; Gilbert, S.M.; Lai, G. Supplier Encroachment as an Enhancement or a Hindrance to Nonlinear Pricing. Prod. Oper. Manag. 2015, 24, 89-109. [CrossRef]

13. Li, J.; Yi, L.; Shi, V.; Chen, X. Supplier encroachment strategy in the presence of retail strategic inventory: Centralization or decentralization? Omega 2020, 98, 102213. [CrossRef]

14. Zhang, J.; Li, S.; Zhang, S.; Dai, R. Manufacturer encroachment with quality decision under asymmetric demand information. Eur. J. Oper. Res. 2019, 273, 217-236. [CrossRef]

15. Hotkar, P.; Gilbert, S.M. Supplier Encroachment in a Nonexclusive Reselling Channel. Manag. Sci. 2021, 67, 5821-5837. [CrossRef]

16. Dan, B.; Liu, C.; Xu, G.; Zhang, X. Pareto Improvement Strategy for Service-Based Free-Riding in a Dual-Channel Supply Chain. Asia-Pac. J. Oper. Res. 2014, 31, 1450050. [CrossRef]

17. Liu, Y.; Zhang, Z.J. Research Note-The Benefits of Personalized Pricing in a Channel. Mark. Sci. 2006, 25, 97-105. [CrossRef]

18. Guan, X.; Liu, B.; Chen, Y.j.; Wang, H. Inducing Supply Chain Transparency through Supplier Encroachment. Prod. Oper. Manag. 2019, 29, 725-749. [CrossRef]

19. Li, T.; Xie, J.; Zhao, X.; Tang, J. On supplier encroachment with retailer's fairness concerns. Comput. Ind. Eng. 2016, 98, 499-501. [CrossRef]

20. Cai, G. Channel Selection and Coordination in Dual-Channel Supply Chains. J. Retail. 2010, 86, 22-36. [CrossRef]

21. Yoon, D.-H. Supplier Encroachment and Investment Spillovers. Prod. Oper. Manag. 2016, 25, 1839-1854. [CrossRef]

22. Sun, X.; Tang, W.; Chen, J.; Li, S.; Zhang, J. Manufacturer encroachment with production cost reduction under asymmetric information. Transp. Res. Part E Logist. Transp. Rev. 2019, 128, 191-211. [CrossRef]

23. Sun, X.; Tang, W.; Zhang, J.; Chen, J. The impact of quantity-based cost decline on supplier encroachment. Transp. Res. Part E Logist. Transp. Rev. 2021, 147, 102245. [CrossRef]

24. Arya, A.; Mittendorf, B. Discretionary disclosure in the presence of dual distribution channels. J. Account. Econ. 2013, 55, 168-182. [CrossRef]

25. Huang, S.; Chen, S.; Guan, X. Retailer information sharing under endogenous channel structure with investment spillovers. Comput. Ind. Eng. 2020, 142, 106346. [CrossRef]

26. Wang, J.; Zhuo, W. Strategic information sharing in a supply chain under potential supplier encroachment. Comput. Ind. Eng. 2020, 150, 106880. [CrossRef]

27. Rousseau, D.M.; Manning, J.; Denyer, D. 11 Evidence in Management and Organizational Science: Assembling the Field's Full Weight of Scientific Knowledge Through Syntheses. Acad. Manag. Ann. 2008, 2, 475-515. [CrossRef]

28. Robaty Shirzad, S.; Bell, D. A Systematic Literature Review of Flexible E-Procurement Marketplace. J. Theor. Appl. Electron. Commer. Res. 2013, 8, 49-70. [CrossRef]

29. Busalim, A.H.; Che Hussin, A.R.; Iahad, N.A. Factors Influencing Customer Engagement in Social Commerce Websites: A Systematic Literature Review. J. Theor. Appl. Electron. Commer. Res. 2019, 14, 1-14. [CrossRef]

30. Paciarotti, C.; Torregiani, F. The logistics of the short food supply chain: A literature review. Sustain. Prod. Consum. 2021, 26, 428-442. [CrossRef]

31. Denyer, D.; Tranfield, D. Producing a Systematic Review. In The Sage Handbook of Organizational Research Methods; Sage Publications Ltd.: Thousand Oaks, CA, USA, 2009; pp. 671-689.

32. Rowley, J.; Slack, F. Conducting a literature review. Manag. Res. News 2004, 27, 31-39. [CrossRef]

33. Zhang, T.; Feng, X.; Wang, N. Manufacturer encroachment and product assortment under vertical differentiation. Eur. J. Oper. Res. 2021, 293, 120-132. [CrossRef]

34. Ha, A.; Long, X.; Nasiry, J. Quality in Supply Chain Encroachment. Manuf. Serv. Oper. Manag. 2015, 18, 280-298. [CrossRef]

35. Yang, H.; Luo, J.; Zhang, Q. Supplier encroachment under nonlinear pricing with imperfect substitutes: Bargaining power versus revenue-sharing. Eur. J. Oper. Res. 2018, 267, 1089-1101. [CrossRef] 
36. Zhang, S.; Zhang, J.; Zhu, G. Retail service investing: An anti-encroachment strategy in a retailer-led supply chain. Omega 2019, 84, 212-231. [CrossRef]

37. Yan, W.; Xiong, Y.; Chu, J.; Li, G.; Xiong, Z. Clicks versus Bricks: The role of durability in marketing channel strategy of durable goods manufacturers. Eur. J. Oper. Res. 2018, 265, 909-918. [CrossRef]

38. Li, J.; Hu, Z.; Shi, V.; Wang, Q. Manufacturer's encroachment strategy with substitutable green products. Int. J. Prod. Econ. 2021, 235, 108102. [CrossRef]

39. Liu, B.; Guan, X.; Wang, H.; Ma, S. Channel configuration and pay-on-delivery service with the endogenous delivery lead time. Omega 2019, 84, 175-188. [CrossRef]

40. Cattani, K.; Gilland, W.; Heese, H.S.; Swaminathan, J. Boiling Frogs: Pricing Strategies for a Manufacturer Adding a Direct Channel that Competes with the Traditional Channel. Prod. Oper. Manag. 2006, 15, 40-56. [CrossRef]

41. Xiong, Y.; Yan, W.; Fernandes, K.; Xiong, Z.-K.; Guo, N. “Bricks vs. Clicks": The impact of manufacturer encroachment with a dealer leasing and selling of durable goods. Eur. J. Oper. Res. 2012, 217, 75-83. [CrossRef]

42. Wang, L.; Chen, J.; Song, H. Manufacturer's channel strategy with retailer's store brand. Int. J. Prod. Res. 2020, 59, 3042-3061. [CrossRef]

43. Guan, H.; Gurnani, H.; Geng, X.; Luo, Y. Strategic Inventory and Supplier Encroachment. Manuf. Serv. Oper. Manag. 2018, 21, 536-555. [CrossRef]

44. Mandal, P.; Jain, T. Partial outsourcing from a rival: Quality decision under product differentiation and information asymmetry. Eur. J. Oper. Res. 2021, 292, 886-908. [CrossRef]

45. Li, H.; Leng, K.; Qing, Q.; Zhu, S.X. Strategic interplay between store brand introduction and online direct channel introduction. Transp. Res. Part E Logist. Transp. Rev. 2018, 118, 272-290. [CrossRef]

46. Chen, J.; Pun, H.; Li, W. Using online channel to defer the launch of discount retailing store. Transp. Res. Part E Logist. Transp. Rev. 2018, 120, 96-115. [CrossRef]

47. Zhang, X.; Li, G.; Liu, M.; Sethi, S.P. Online platform service investment: A bane or a boon for supplier encroachment. Int. J. Prod. Econ. 2021, 235, 108079. [CrossRef]

48. Zhang, S.; Zhang, J. Agency selling or reselling: E-tailer information sharing with supplier offline entry. Eur. J. Oper. Res. 2020, 280, 134-151. [CrossRef]

49. Zhang, Z.; Song, H.; Gu, X.; Shi, V.; Zhu, J. How to compete with a supply chain partner: Retailer's store brand vs. manufacturer's encroachment. Omega 2021, 103, 102412. [CrossRef]

50. Wang, N.; Li, Z. Supplier Encroachment with a Dual-Purpose Retailer. Prod. Oper. Manag. 2021, 1-17.

51. Hu, B.; Mai, Y.; Pekeč, S. Managing Innovation Spillover in Outsourcing. Prod. Oper. Manag. 2020, 29, 2252-2267. [CrossRef]

52. Dong, B.; Tang, W.; Zhou, C.; Ren, Y. Is dual sourcing a better choice? The impact of reliability improvement and contract manufacturer encroachment. Transp. Res. Part E Logist. Transp. Rev. 2021, 149, 102275. [CrossRef]

53. Dong, B.; Tang, W.; Zhou, C.; Ren, Y. Should original equipment manufacturer assist noncompetitive contract manufacturer to expand capacity? Omega 2021, 103, 102420. [CrossRef]

54. Lin, F.; Qin, X.; Pu, X.; Zhu, W.; Zhuo, X. Effects of in-house production on channel structures in a co-opetitive supply chain under supply uncertainty. Omega 2021, 103, 102426. [CrossRef]

55. Cui, Q. Quality investment, and the contract manufacturer's encroachment. Eur. J. Oper. Res. 2019, 279, 407-418. [CrossRef]

56. Li, T.; Xie, J.; Zhao, X. Supplier encroachment in competitive supply chains. Int. J. Prod. Econ. 2015, 165, 120-131. [CrossRef]

57. Chen, K.-Y.; Kaya, M.; Özer, Ö. Dual Sales Channel Management with Service Competition. Manuf. Serv. Oper. Manag. 2008, 10, 654-675. [CrossRef]

58. Zhao, D.; Li, Z. The impact of manufacturer's encroachment and nonlinear production cost on retailer's information sharing decisions. Ann. Oper. Res. 2017, 264, 499-539. [CrossRef]

59. Xue, M.; Zhang, J.; Zhu, G. Quantity decision timing with spillover effect and asymmetric demand information. Transp. Res. Part E Logist. Transp. Rev. 2020, 142, 102048. [CrossRef]

60. Li, Q.; Li, B.; Chen, P.; Hou, P. Dual-channel supply chain decisions under asymmetric information with a risk-averse retailer. Ann. Oper. Res. 2015, 257, 423-447. [CrossRef]

61. Huang, S.; Chen, S.; Xiao, L. Manufacturer product quality information disclosure with channel encroachment in the E-commerce age. Manag. Decis. Econ. 2020, 41, 744-761. [CrossRef]

62. Gao, L.; Guo, L.; Orsdemir, A. Dual-Channel Distribution: The Case for Cost Information Asymmetry. Prod. Oper. Manag. 2020, 30, 494-521. [CrossRef]

63. Li, B.; Jiang, Y. Impacts of returns policy under supplier encroachment with risk-averse retailer. J. Retail. Consum. Serv. 2019, 47, 104-115. [CrossRef]

64. Hotelling, H. Stability in Competition. Econ. J. 1929, 39, 41-57. [CrossRef]

65. El-Ansary, A.I.; Stern, L.W. Power Measurement in the Distribution Channel. J. Mark. Res. 1972, 9, 47-52. [CrossRef]

66. Arya, A.; Mittendorf, B.; Ramanan, R.N.V. Beyond Profits The Rise of Dual-Purpose Organizations. Account. Rev. 2019, 94, 25-43. [CrossRef] 